\title{
MODELLING OF VOLCANIC ERUPTIONS ON TITAN
}

\author{
Solomonidou A. ${ }^{1,2,3}$, Fortes A.D. ${ }^{3}$, Kyriakopoulos K. ${ }^{1}$ \\ ${ }^{1}$ National \& Kapodistrian University of Athens, Department of Geology and Geoenvironment, \\ Athens, Greece (asolomonidou@geol.uoa.gr)., \\ ${ }^{2}$ LESIA, Observatoire de Paris - Meudon, Meudon Cedex, France (Athena.Coustenis@obspm.fr)., \\ ${ }^{3}$ University College London, Department of Earth Sciences, London, UK.
}

\begin{abstract}
Observations by the Visual Infrared Spectrometer instrument (VIMS) aboard the Cassini mission have indicated the possible presence of $\mathrm{CO}_{2}$ ice on the surface on Titan, in areas which exhibit high reflectance in specific spectral windows (McCord et al., 2008). Two of the bright spots of significance are located within the Xanadu region - Tui Regio (located at $20^{\circ} \mathrm{S}, 130^{\circ} \mathrm{W}$ ) and Hotei Regio (located at $26^{\circ} \mathrm{S}, 78^{\circ} \mathrm{W}$ ), and there is a further spot situated in proximity to Omacatl Macula (Hayne et al., 2008). Explosive volcanic eruptions of a cryomagma containing $\mathrm{H}_{2} \mathrm{O}$ and $\mathrm{CO}_{2}$ are modelled for several potential scenarios regarding entrained $\mathrm{CO}_{2}$ clathrates. The model yielded a range of values corresponding to the fragmentation pressure in the lava conduit, the velocity of the exploding cryomagma, the height of the associated lava fountain and the potential distance covered by ejecta. The results show that a single vent source does not possess the force required to cover an area resembling Hotei Regio or Tui Regio. Therefore, we consider alternative origins: the area may have been resurfaced by small $\mathrm{CO}_{2}$ grains resulting from multiple explosive eruptions emanating from a zone of weakness (Hayne et al., 2008); the characteristics of the area are consequential of an eruption of cryomagma with $\mathrm{CO}_{2}$ and $\mathrm{NH}_{3}$ components (McCord et al., 2008); or finally, long term seasonal winds transferred small $\mathrm{CO}_{2}$ grains and distributed them within the limits of Tui Regio area.
\end{abstract}

\section{A brief introduction to Icy Moons}

A significant proportion of the planetary bodies found within our solar system have been subject to observation, analysis, and mapping as well as classification, based on their characteristics. These achievements were the result of observations dating from ancient times until the present day but were accomplished predominantly through exploratory missions such as Voyager, Galileo, Cassini and many more. The three aforementioned missions provided information about the moons of several planets situated beyond the orbit of Mars. These 'icy moons' have distinctive characteristics, which are unique in our solar system (Lorenz, 2006).

Icy moons are small celestial bodies whose surfaces are partially, if not principally, covered by ice. They exhibit some features similar to planets (Johnson, 2004). Representative bodies of this category include several satellites of Jupiter, Saturn, Uranus, Neptune (Fig.1). The most remarkable icy moons are, respectively to the planets mentioned, Ganymede, Triton, Miranda and Titan with a variety of size, composition and temperature (Johnson, 2004). In recent times, it has been confirmed that the majority of satellites orbiting the outer planets have an icy appearance with a combined structure of rock and $\mathrm{H}_{2} \mathrm{O}$ ice and/or $\mathrm{NH}_{3}$ ice and/or $\mathrm{CO}_{2}$ ice. It was thought that, due to the abun- 


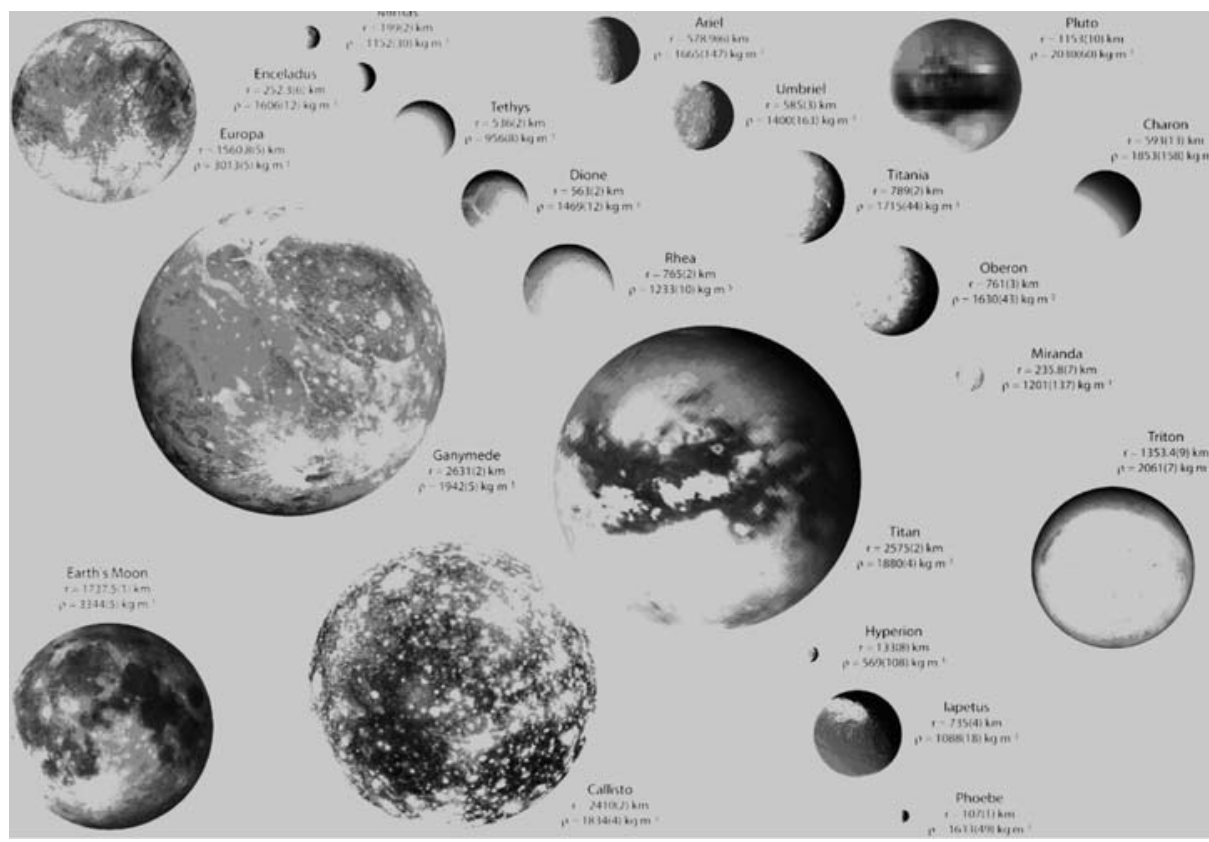

Fig. 1: Icy satellites

dance of water ice, the geology of these bodies would be simple, or rather simpler than Earth's; however, subsequent images have shown complex surfaces with several notable morphological formations. Furthermore, the composition as well as the structure of the surfaces of the icy moons is dependent upon geological and geophysical factors (Johnson, 2004).

\section{The Saturnian moons}

Long-lasting investigations showed that one of the most fascinating characteristics of the Saturnian icy worlds is their complex, dynamic and Earth-like geology. Intervent and layered plains, icy flows, impact units, extensive ridges and grooves are the effects of endogenous and exogenous intense dynamic processes. On the surfaces of Titan and Enceladus, which geologically are the most interesting satellites, these processes are expressed in the form of cryovolcanoes, geysers and tectonic features. The activity of cryovolcanism on Titan can be described analogous to Earthy volcanism, where methane, as a product of the volcanic activity, is the main component of Titan's unique organic chemistry laboratory (Johnson, 2004). In particular, Titan's atmosphere is mostly nitrogen but there are also methane and many other organic compounds. The problem that arises regarding the presence of methane on Titan is the source that feeds and maintains the surface as well as the atmosphere. On Earth today, it is life itself that refreshes the methane supply through the metabolism of many organisms. On Titan there is no living life that could provide the satellite with methane as a by-product, suggesting that there should be a reservoir of methane within Titan that interacts with the atmosphere.

Methane outgassing from the interior or from the subsurface could constitute the missing reservoir to explain the presence of gaseous methane in today's atmosphere. On the southern limb of Enceladus an impressive phenomenon of icy geysers is present. Instruments on the Cassini spacecraft discovered these icy plumes during close encounters with Enceladus (Matson et al., 2007). They could 

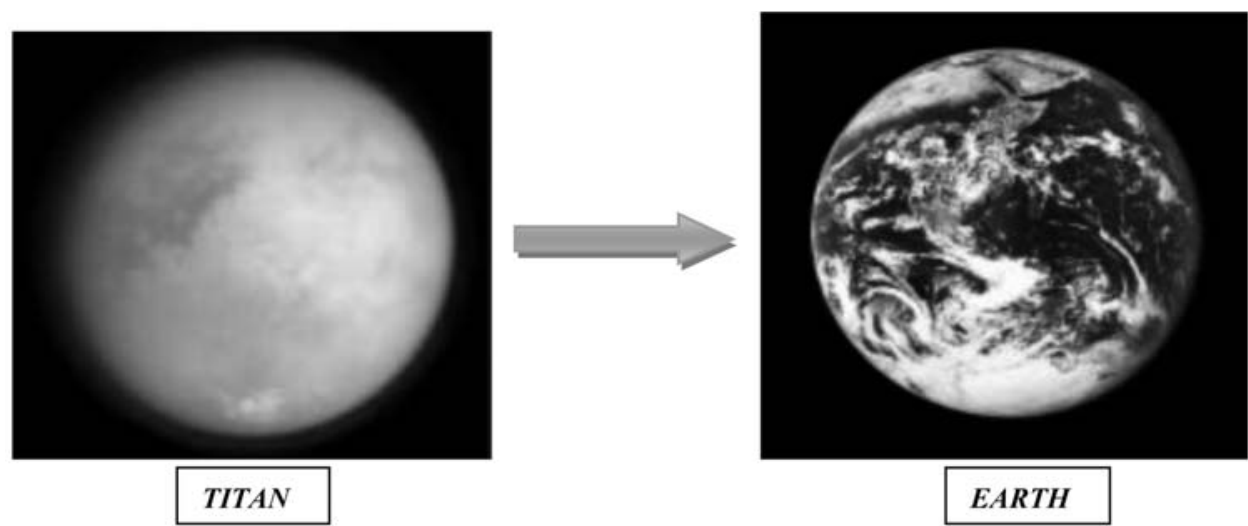

Fig. 2: Earth-like Titan (retrieved from NASA / Goddard Space Flight center).

be due to condensation of the vapor escaping from a water source and stream through the cracks in the ice crust before heading into space and supposedly populate Saturn's E-ring (Kempf et al., 2008). Another moon that displays fascinating geological features is Iapetus, presenting a phenomenon called 'two-tone' coloration due to intense color differences of the leading (dark) and trailing (bright) hemispheres. The dark material is believed to be a residual product of the water ice evaporation on the surface. The event that caused this could be the exposure to sunlight. Alternatively, thermal anomalies after bombardment of micrometeorites that crossed Iapetus's orbit emanating from Phoebe could have caused the evaporation. Iapetus's surface morphology is exceptionally interesting as it presents a high equatorial ridge and impact craters with variety in size on both dark and bright sides. The ridge is a unique geomorphological feature as it rises more than $20 \mathrm{~km}$ above the plains and consists of a complex system of parallel ridges, surrounding plains and isolated peaks (Porco et al., 2005). Another Saturnian icy moon that is heavily bombarded and grooved, is Rhea (Wagner et al., 2007). This moon geologically is similar to Dione and there are in both potential areas of past cryovolcanic activity. Cassini's spacecraft investigation implied that the level of active endogenic process is extremely low, although the surficial features suggest a world that in the past was geologically active similar to the present situation on Titan and Enceladus. The Saturnian moons suggest unique areas of geological research due to their active interiors or/and their complex formed surfaces. Almost every geological activity and feature present on Earth has so far been observed on these fascinating worlds, acting more dynamically, creating extremely active and powerful systems.

\section{Titan}

Titan is the largest moon of Saturn and the second largest in the Solar System after Jupiter's Ganymede. It is primarily composed of rocky material and water ice and exhibits a variety of surface formations such as mountains, lakes, craters, dunes and many more (Johnson, 2004). One of the moon's exceptional characteristics, that enhance its allure for exploration, is the existence of stable bodies - lakes - of surface liquid (Stofan et al., 2007). Previous to this discovery, such features had only been identified on Earth's surface (Fig.2). The atmosphere of Titan is also unique, as it is the only moon known to have an atmosphere with a greater density than that of Earth (Coustenis and Taylor, 1999), and the only object that shows stable bodies of surface liquid (Stofan et al., 2006). Of even more importance is the recent discovery of cryovolcanism as an outstanding characteristic of Titan, as well as the possibility that the moon harbours a prebiotic environment rich in complex organic chemistry (Fortes et al., 2007). 

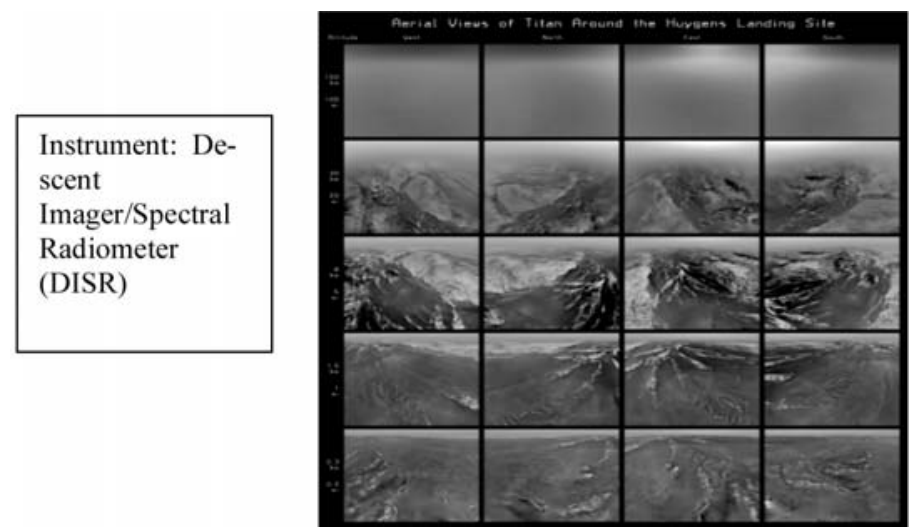

Fig. 3: Huygens's view of Titan's surface from five altitudes (retrieved from NASA).

Titan has been under detailed investigation for the past 17 years. Initially this was carried out by NASA's Hubble Space Telescope, which showed for the first time that an extensive bright continuous land exists on the leading hemisphere. Likewise, observations using several land-based telescopes shed light on additional information concerning the atmosphere and the surface (Coustenis and Taylor, 1999).

The most recent and crucial approach to Titan remains in commission - NASA's Cassini-Huygens spacecraft, on mission to the Saturn system. The data from instruments aboard this craft supplied information regarding Titan's atmosphere, surface composition and structure (Fig.3) as well as concerning the possible existence of evidence of life on this icy satellite (Lorenz and Mitton, 2008).

\section{Geological processes on Titan}

Titan's surface demonstrates a variety of geological features and formations, which frequently contain water ice or elements that render their presence particularly interesting. Chronologically the surficial geological features are young as well as complicated and unique for a celestial satellite (Mahaffy, 20005). Before 1997, several hypotheses predicted cryovolcanic activity, impact craters and even large stable liquid bodies. Further to the data collected by the Cassini mission, these assumptions were confirmed. In general, Titan's surface appears to have smooth and rough areas of various altitudes, which include volcanic features such as cryovolcanoes and impact craters that are intermittently filled by atmospheric precipitations. In addition, the satellite exhibits topographic features such as rims and edges and tectonic features filled with material by means of thermodynamic processes (Johnson, 2004). These features and formations will be examined individually forthwith.

Cryovolcanism: Cryovolcanism is considered to be one of the principal geological processes that have shaped several of the icy moons' surfaces. This activity can be described as ice-rich volcanism, while the cryovolcanic ejecta is referred to as cryomagma. This volcanic melt appears in the form of icy cold liquid and, in some cases, as partially crystallised slurry (Kargel, 1994). Cryovolcanic activity on icy satellites presents a controversial scientific issue and interest within the scientific community is ever increasing, almost certainly due to the postulation that cryomagma may be relevant to the formation of prebiotic compounds (Fortes, 2000). As a pre-life indicator, prebiotic compounds can possibly be connected to, and considered as evidence for, the existence of extraterrestrial life (Lopes et al., 2007). The composition of cryomagma is still unknown, due to the lack of in situ measurements. The general opinion suggests that the composition of cryomagma on Titan is likely primarily a mix- 


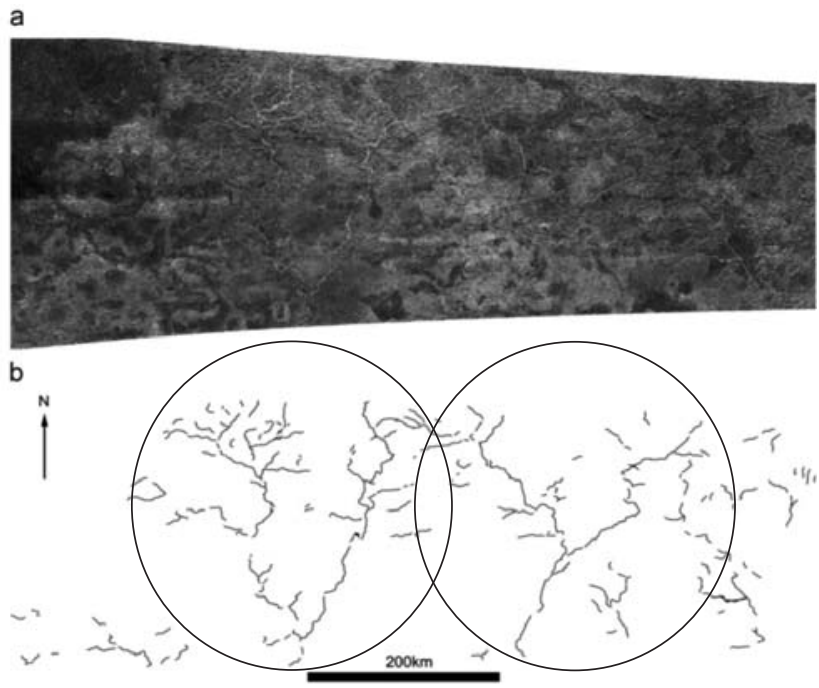

Fig. 4: Fluvial Network Dendritic drainages (Lorenz et al., 2008).

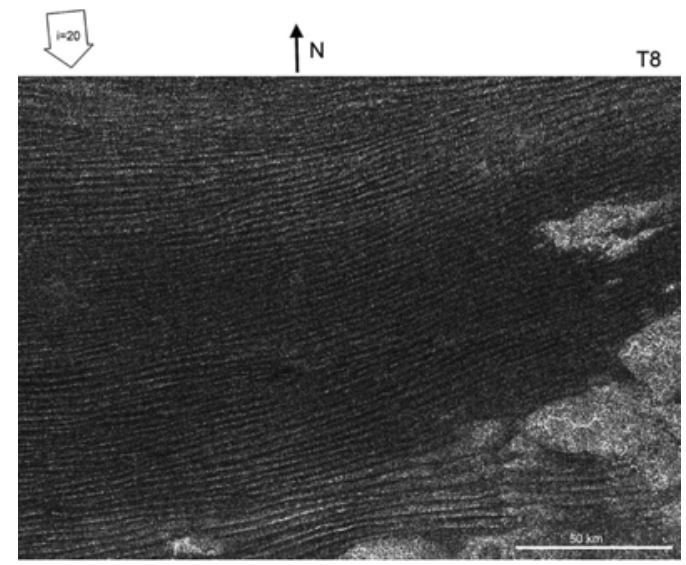

Fig. 5: Equatorial sand sea on Titan (Radebaugh, 2009).

ture of water ice and ammonia (Lopes et al., 2007). Other theories suggest mixtures of a/ $\mathrm{H}_{2} \mathrm{O}$ and $\left(\mathrm{NH}_{4}\right) 2 \mathrm{SO}_{4}$ (Mahaffy, 2005) and b/ $\mathrm{H}_{2} \mathrm{O}$ and $\mathrm{CO}_{2}$ (McCord et al., 2008). The icy moons on which features of cryovolcanism have been identified are Europa, Ganymede, Enceladus and Titan.

Geomorphology: Fluvial processes. The Cassini radar observations presented the fluvial features and their flow directions on the Xanadu area of Titan (Fig. 6). The fluvial processes on Titan's surface present a major geodynamic activity that contributes to the satellite's morphology. This fluvial network extends over $400 \mathrm{~km}$ while it presents a dendritic morphology (Fig. 4). The dendritic network drainage is the pattern formed by the streams, rivers and lakes in a particular "watershed". In this case incisions were not observed but a well-developed branching structure on both channels (red and green circle) is present (Lorenz et al., 2008).

Aeolian processes: A sand dune is a semi-permanent accumulation of loose sand that forms in areas 


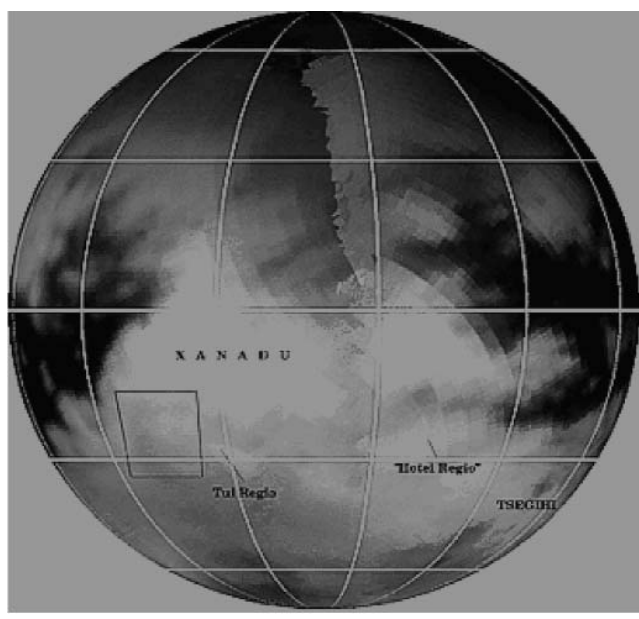

Fig. 6: Titan's possibly active cryovolcanic regions (Barnes et al., 2006).

where the wind tends to blow in one direction, at velocities high enough to move sand, across a land surface that permits sand to amass in a regular and consistent form. The sand composition is possibly a mixture of organic materials and ice grains (Radebaugh et al., 2008).

This geological phenomenon presents two kinds of linear features (Fig. 5). A Cassini Radar image $\left(8^{\circ} \mathrm{S}, 264^{\circ} \mathrm{W}\right)$ where dark linears are the sides of dunes facing away from the radar and bright linears are due to direct reflection of a radar-facing slope (Radebaugh, 2009).

\section{Instrumentation}

The visual and infrared mapping spectrometer is the primary instrument that brought evidence for the $\mathrm{CO}_{2}$ presence on Titan's surface. In the Cassini-Huygens mission, the visual and infrared mapping spectrometer was used for perform a multidisciplinary investigation of the Saturnian system including the surface and atmosphere of Titan (Brown et al., 2004). Essentially, the observations were made using techniques of spectroscopy (near-infrared imaging) and spectrophotometry (high speed) (Brown et al., 2004).

\section{Cryovolcanic Areas of Interest}

\subsection{Tui Regio}

The Tui Regio, also referred to as 'The Smile' (Fig.6), is one of the areas where an anomalously bright spot was observed, and therefore constitutes a component of the most reliable evidence yet obtained concerning the presence of carbon dioxide on Titan's surface. It is circa $150 \mathrm{~km}$ wide, extends 1500 $\mathrm{km}$ in an east-west direction and situated near $125^{\circ} \mathrm{W} 24^{\circ} \mathrm{S}$ (Barnes et al., 2006). Nelson et al. (2007) suggest that this region may be associated with zones of fluctuating brightness while Hayne et al. (2008) propose that the Tui Regio could be an active centre of cryovolcanism. The evidence stands that the spectral reflectance in the $5 \mu \mathrm{m}$ window is compatible to $\mathrm{CO}_{2}$ (Barnes et al., 2006) while other spectral images of candidate materials (ices) such as $\mathrm{H}_{2} \mathrm{O}$ and $\mathrm{CH}_{4}$ seems incompatible (Grundy et al., 2002). Although the presence of $\mathrm{CO}_{2}$ on the surface has not yet been confirmed.

\subsection{Hotei Regio}

Other than 'The Smile' bright spot on Titan's surface, telescope investigations and Cassini VIMS data showed another bright spot, lying between the mid-latitude zone and the equatorial zone south of Xanadu 
$\left(110^{\circ} \mathrm{W} 15^{\circ} \mathrm{S}\right)$. Hotei Regio (Fig. 6) extends over $450 \mathrm{~km}$ (N-S) and $400 \mathrm{~km}$ (W-E) (Barnes et al., 2006). The region is particularly conspicuous as it is brighter than the whole area of Xanadu at all wavelengths, especially those greater than 1.6 $\mu \mathrm{m}$ (Roe et al., 2004). In addition, whilst the Keck Observatory imaged this unusual feature on Titan's surface at $2 \mu \mathrm{m}$, the VIMS team presented collected data through the use of colour composites, demonstrating its striking bright characteristics. In the maps created by combining these colour composites, using data from the $5 \mu \mathrm{m}$ atmospheric window, the feature of Hotei Regio is bright red (Barnes et al., 2006).

\section{Modelling}

On Earth, the concentrations of different volcanic gases can vary considerably from one volcano to the next. Typically, water vapour is the most abundant volcanic gas, followed by carbon dioxide and sulphur dioxide. Other principal volcanic gases include hydrogen sulphide, hydrogen chloride, $\mathrm{N}_{2}$, $\mathrm{O}_{2}$ and hydrogen fluoride (Rosi et al., 2003). Also, noble gases and helium from primordial Earth degassing. A large number of minor and trace gases are also found in volcanic emissions. These include hydrogen, carbon monoxide, halocarbons, organic compounds, and volatile metal chlorides (Bryson and Goodman, 1980).

Fortes et al. (2007) suggest methane gas, carbon monoxide and nitrogen as possible volatile volcanic gases candidates in Titan's magma. In this study, employing a model that we named the ' $\mathrm{CO}_{2}$ model', we suggest one more candidate - carbon dioxide.

The presence of the 'bright spots' on Titan's surface comprise the evidence that has generated the assumption of $\mathrm{CO}_{2}$ as a component of Titan's interior as well as the possible origin of cryovolcanism. The modelling of $\mathrm{CO}_{2}$ imparts substantial amounts of data that, in combination with surface observation, could show whether or not a possible cryovolcanic activity involving a mixture of $\mathrm{CO}_{2}$ and $\mathrm{H}_{2} \mathrm{O}$ could have created the observed ' $\mathrm{CO}_{2}$ ice" products. These data include; calculations of fragmentation depths, possible velocities according to the amount of clathrates in the mixture, approximate calculations of the maximum height reached by the lava fountain, and the distance at which ejecta could be deposited. The results will contribute to the correlation of the mathematical data with the observation evidence present on Titan's surface. The identification of $\mathrm{CO}_{2}$ as a component of the surface will further our understanding of the satellite's composition and impose boundary conditions on its evolution. More specifically, such research will provide a holistic overview of cryovolcanism and its role on Titan.

List of properties:

Equations:

- $\mathrm{P}=\operatorname{ggh}(1)(\mathrm{P}$ is the difference between the pressure and the initial pressure within the volcanic conduit)

- $\beta^{-1}=\left[\left(n_{c} R T\right) / m P\right]+\left[\left(1-n_{c}\right) / \varrho_{H 2 O}\right]$ (2) (Density of the bulk magma)

- $\mathrm{V}_{\mathrm{b}}=1-\beta\left[\left(1-\mathrm{n}_{\mathrm{m}}\right) / \varrho_{\mathrm{H} 2 \mathrm{O}}\right]$ (3) (Bubble volume fraction)

- $(\mathrm{g} \mathrm{h})=(\mathrm{Pf}-\mathrm{Pv}) / \mathrm{Q}_{\text {crust }}(4)$ (Potential energy change per unit mass of magma $)$

- $0.5 \mathrm{u}_{\mathrm{v}}{ }^{2}=\left(\mathrm{n}_{\mathrm{m}} \mathrm{RT} / \mathrm{m}\right) \ln \left(\mathrm{P}_{\mathrm{F}} / \mathrm{P}_{\mathrm{V}}\right)+\Delta \mathrm{P}\left[\left(1-\mathrm{n}_{\mathrm{m}} / \varrho_{\text {magma }}\right)-1 / \varrho_{\text {crust }}\right]$ (5) (Kinetic energy per unit mass)

- $\mathrm{H}=\mathrm{u}^{2} / 2 \mathrm{~g}(6)$ (Lava fountain height)

- $\mathrm{d}=\mathrm{u}^{2} \sin (2 \theta) / \mathrm{g}(7)$ (Total horizontal distance).

Using equations we have calculated the horizontal distance, $d$, that ejecta could cover after an eruption for a range of velocities (Table 1). The angle of ejecta trajectory is considered in the range of $0-80^{\circ}$ and $\mathrm{g}$ is $1.354 \mathrm{~m} / \mathrm{s}^{2}$. Plot 1 shows the trajectory of ejecta, which extrudes from an eruption with a velocity 
Table 1. Integral table with values resulted from all the possible scenarios

\begin{tabular}{|c|c|c|c|c|}
\hline \begin{tabular}{|c|} 
Dissolved $\mathrm{CO}_{2}$ \\
clathrate scenarios
\end{tabular} & & & & \\
\hline $\begin{array}{c}\text { Volume Fraction of } \\
\text { exsolved } \mathrm{CO}_{2}\end{array}$ & $\begin{array}{c}\text { Entrained } \\
\text { clathrates }(\mathrm{wt} \%)\end{array}$ & $\begin{array}{l}\text { Fragmentation } \\
\text { depth }(\mathrm{m})\end{array}$ & $\begin{array}{l}\text { Eruption velocity } \\
\qquad(\mathrm{m} / \mathrm{s})\end{array}$ & $\begin{array}{l}\text { Lava fountain } \\
\text { height (m) }\end{array}$ \\
\hline 0 & 0 & & 0 & 0.00 \\
\hline 0.75 & 44 & 0 & 5.2 & 9.82 \\
\hline 0.75 & 50 & 6.25 & 12.5 & 57.85 \\
\hline 0.75 & 55 & 22.93 & 24 & 213.02 \\
\hline 0.75 & 60 & 44.31 & 35.2 & 457.80 \\
\hline 0.75 & 65 & 46.56 & 39.3 & 571.45 \\
\hline 0.75 & 70 & 64.43 & 48.3 & 862.12 \\
\hline 0.75 & 75 & 90.06 & 58.6 & 1270.18 \\
\hline 0.75 & 80 & 107.62 & 66.3 & 1625.65 \\
\hline 0.75 & 85 & 111.56 & 70.8 & 1850.89 \\
\hline 0.75 & 90 & 136.25 & 79.6 & 2338.90 \\
\hline
\end{tabular}

Table 1 summarizes the results of the equations used after the appropriate processing in our model.

List of properties:

\begin{tabular}{|l|c|}
\hline $\mathrm{CO}_{2}$ Model TITAN & Values \\
\hline Density of the crust & $1000 \mathrm{~kg} / \mathrm{m}^{3}$ \\
\hline Density of the cryomagma & $1000 \mathrm{~kg} / \mathrm{m}^{3}$ \\
\hline Density of $\mathrm{CO}_{2}$ gas & $1,87 \mathrm{~kg} / \mathrm{m}^{3}$ \\
Molecular mass of $\mathrm{CO}_{2}$ & $0,044 \mathrm{~kg} / \mathrm{mol}$ \\
\hline Gas constant & $8,314 \mathrm{~kg} / \mathrm{mol}$ \\
\hline Magma Temperature & $273 \mathrm{~K}$ \\
\hline Mass of Titan & $1,345 \mathrm{E}+23 \mathrm{~kg}$ \\
\hline Surface gravity & $1,354 \mathrm{~m} / \mathrm{s}^{2}$ \\
\hline
\end{tabular}

of $5.2 \mathrm{~m} / \mathrm{s}$ - the slowest eruption velocity calculated for a potential eruption in the ' $\mathrm{CO}_{2}$ model'.

\section{Discussion and Modelling}

The Visual and Infrared Mapping Spectrometer data suggesting the $\mathrm{CO}_{2}$ presence on the surface of Titan ("bright-spots") generated the assumption of $\mathrm{CO}_{2}$ being a component of the satellite's interiors and therefore the possible origin of cryovolcanism. Since exsolution of volatiles, mainly $\mathrm{H}_{2} \mathrm{O}$ and $\mathrm{CO}_{2}$ as well as other volcanic gas species are common during volcanic activity on Earth we have used similar "explosivity" modelling to predict cryovolcanic activity results on Titan (Table 1) assuming a constant volume fraction of exsolved $\mathrm{CO}_{2}$ and an increasing by $5 \mathrm{wt} \%$ amount of clathrate (which is a chemical substance 


\section{Ejecta's trajectory (eruption velocity $5.2 \mathrm{~m} / \mathrm{s}$ )}

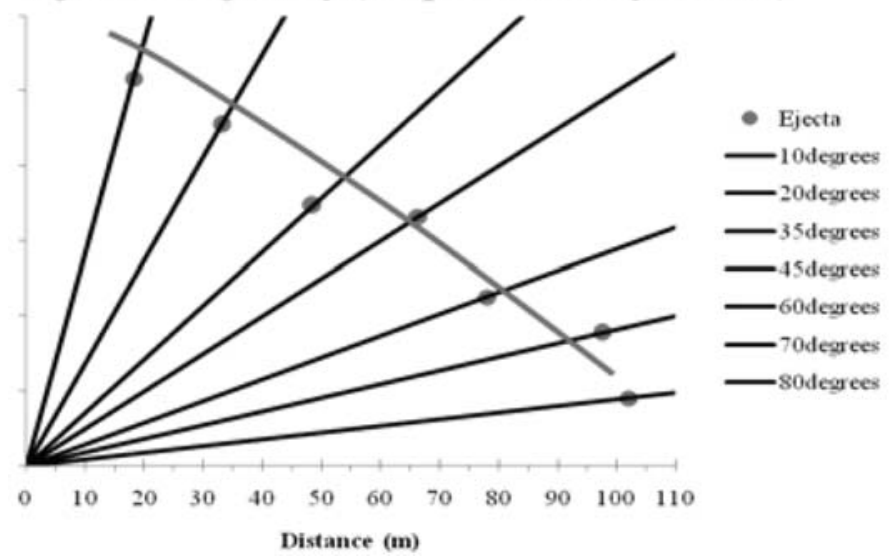

Plot 1: Trajectory of extruded ejecta and its path to the surface.

consisting of a lattice of one type of molecule trapping and containing a second type of molecule). This ' modelling of $\mathrm{CO}_{2}$ "' imports substantial amounts of data that, in combination with surface observations, could show whether or not possible cryovolcanic activity involving a mixture of $\mathrm{CO}_{2}$ and $\mathrm{H}_{2} \mathrm{O}$ could have created the observed " $\mathrm{CO}_{2}$-ice" products. These data include: calculations of fragmentation depths, estimations of eruption velocities as well as the height of the lava fountain for every case scenario.

\section{Conclusions}

This study has focused on evidence from 'Hotei Regio' and Tui Regio, in order to correlate the data provided from the ' $\mathrm{CO}_{2}$ model' with observed data, gathered via VIMS imaging. The variety of possible eruptions was limited because of restrictions on the likely cryomagmatic composition, since it is doubtful that large quantities of " $\mathrm{CO}_{2}$-ice" are present at the observed bright spots (Sotin et al., 2005). Therefore, the results support a conclusion of rapid eruptions and ejecta that travels within a range of 9-24km (Appendix: Table A) from the vent. It is possible that the remaining area of Hotei Regio, which extends approximately $400 \mathrm{~km}$ in the latitudinal direction and $450 \mathrm{~km}$ longitudinally (Barnes et al., 2006), is covered by products of multiple episodic eruptions of cryomagma containing a mixture of $\mathrm{NH}_{3}$ and $\mathrm{CO}_{2}$ (Hayne et al., 2008). An alternative origin of the deposits could be provided by seasonal winds that transport and disperse small $\mathrm{CO}_{2}$ grains within the area.

\section{Future work}

Since the "Cassini-Huygens" mission at Titan, interest in future missions has increased continuously. Currently, the "Cassini Equinox mission"' remains operational with frequent flybys over Titan. Future flybys will bring in additional observations and spectral data from the VIMS instrument and also allow a continuous observation of the bright spots, thus aiding interpretation of the current data. A potential further extension of the Cassini mission will offer valuable supplementary data and observations on the seasonal variations of Titan's atmosphere and surface. As aforementioned, this will prove helpful in understanding the behaviour of ejecta resulting from a potential eruption and elucidate its relationship with surface winds. Titan has so intrigued the scientific community that several other proposals for future missions have been made by scientists all over the world. Coustenis et al. (2009) suggest a new study of Titan with a combination of two missions. The design of the Titan Saturn System Mission (TSSM), which will study Titan as a system, is based on the scientific and technological achievements of the Cassini-Huy- 
gens mission. It aims to investigate Titan specifically, by obtaining measurements that Cassini-Huygens was unable to, via full close-up and in situ coverage over long periods of time (Coustenis et al., 2009). The high-resolution coverage of the surface could provide valuable data of increased detail regarding the presence of $\mathrm{CO}_{2}$ on the surface and the morphology of the $\mathrm{CO}_{2}$ products, such as flows or ejecta.

\section{References}

Barnes, J.W., Brown, R. H., Turtle, E.P., McEwen, A.S., Lorenz, R. D., Janssen, M., Schaller, E.M., Brown, M.E., Buratti, B.J., Sotin, C., Griffith, C., Clark, R., Perry, J., Fussner, S., Barbara, J., West, R., Elachi, C., bounchez, A.H., Roe, H.G., Baines, K.H., Bellucci, G., Bibring, J.P., Capaccioni, F., Cerroni, P., Combes, M., Coradini, A., Cruikshank, D.P., Drossart, P., Formisano, V., Jaumann, R., Langevin, Y., Matson, D., McCord, T.B., Nicholson, P.D., Sicardy, B., 2005. A 5-Micron-Bright Spot on Titan: Evidence for Surface Diversity. Science, 310, 92-95.

Barnes, J.W., Radebaugh, J., Buratti, B.J., Sotin, C., Le Mouelic, S., Rodriguez, S., Turtle, E.P., Perry, L., Clark, R., Baines, K.H., Nicholson, D., 2006. Cassini observations of flow-like features in western Tui Regio, Titan. Geophys. R. Lett., 33, L16204.

Brown, R.H., Baines, K.H., Bellucci, G., Borbing, J.P., Buratti, B.J., Capaccioni, F., Cerroni, P., Clark, R.N., Coradini, A., Cruikshank, D.P., Drossart, P., Formisano, V., Jaumann, R., Lamgevin, Y., Matson, D.L., McCord, T.B., Mennella, V., Miller, E., Nelson, R.M., Nicholson, P.D., Sicardy, B. and Sotin, C., 2004 . The Cassini visual and infrared mapping spectrometer (VIMS) investigation. Space Science Reviews, 115, 112-168.

Bryson, R.A., Goodman, B.M., 1980. Volcanic Activity and Climatic Changes. Science, 207, 1041-1044.

Coustenis, A., Taylor, F., 1999. Book: Titan: The Earth-Like Moon. Series on Atmospheric, Oceanic and Planetary Physics - Vol. 1.

Coustenis, A. et al., 2009. THE JOINT NASA-ESA TITAN SATURN SYSTEM MISSION (TSSM) STUDY. 40th Lunar and Planetary Science Conference, id:1060.

Fortes, A.D., 2000 Exobiological implications of a possible subsurface ocean inside Titan. Icarus, 146, 444-452.

Fortes, A.D., Grindrod, P.M., Trickett S.K, Vo cadlo L., 2007 Ammonium sulfate on Titan: Possible origin and role in cryovolcanism. Icarus, 188, 139-153.

Grundy, W.M., Schmitt, B., Quirico, E., 2002. The temperature-dependent spectrum of methane ice I between 0.7 and $5 \mu \mathrm{m}$ and opportunities for nearinfrared remote thermometry. Icarus, 155, 486-496.

Hayne, P., McCord, T.B., Sotin, C., Barmatz, M., Mielke, R., Combe, J.P., Hansen, G. B., 2008. Titan: Observational Constraints on Cryovolcanism. 39th LPSC, LPI Contribution No. 1391, 2010.

Johnson, T., 2004. Geology of the icy satellites. Space science reviews, 166, 401-420.

Kargel, J.S., 1994. Cryovolcanism on the icy satellites. Earth, Moon, and Planets, 67, 1-3.

Kempf, S., Beckmann, U., Schmidt, J., 2008. The E ring in the vicinity of Enceladus. Icarus, 193, 420-437.

Lopes, R.M.C., Mitchell, K.L., Stofan, E.R., Lunine, J.I, Lorenz, R., Paganelli, F., Kirk, R.L, Wood, C.A, Wall, S.D., Robshaw, L.E., Fortes, A.D., Neish, C.D., Radebaugh, J., Reffet, E., Ostro, S.J., Elachi, C., Allison, M.D., Anderson, Y., Boehmer, R., Boudin, G., Callahan, P., Encrenaz, P., Flamini, E., Francescetti, G., Gim, Y,m Hamilton, G., Hensley, S., Janssen, M.A., Johnson, W.T.K., Kelleher, K., Muhleman, D.O., Ori, G., Orosei, R., Picardi, G., Posa, F., Roth, L.E., Seu, R., Shaffer, S., Soderblom, L.A., Stiles, B., Vetrella, S., West, R.D., Wye, L., Zebker, H.A., 2007. Cryovolcanic features on Titan's surface as revealed by the Cassini Titan Radar Mapper. Icarus, 186, 395-412.

Lorenz, R.D., 2006. The exploration of Titan. Johns Hopkins APL Technical Digest, 27, 113-144.

Lorenz, R.D. and Mitton, J., 2008. Book: Titan Unveiled. Princeton University Press.

Lorenz, R.D., Mitchell, K.L., Kirk, R.L., Hayes, A.G., Aharonson. O., Zebker, H.A., Paillou, P., Radebaugh, J., Lunine, J., Jannsen, M.A., Wall, S.D., Lopes, R.M., Stiles, B., Ostro, S., Mitri, G., Stofan, E.R. and the Cassini 
RADAR team. 2008a. Titan's inventory of organic surface materials. Geophysical research letters, 38, 2-17. Mahaffy, R., 2005. Intensive Titan Exploration Begins. Science, 308, 969-970.

Matson, D.L., Castillo, J.C., Lunine, J., Johnson, T., 2007. Enceladus' plume: Compositional evidence for a hot interior. Icarus, 187, 569-573.

McCord, T.B., Hayne, P., Combe, J.P., Hansen, G. B., Barnes, J. W., Rodriguez, S., Le Mouelic, S., Baines, E., Buratti, B. J., Sotin, C., Nicholson, P., Jaumann, R., Nelson, R., and the Cassini VIMS TEAM. 2008. Titan's surface: Search for spectral diversity and composition using the Cassini VIMS investigation. Icarus, 194, 212-242.

Nelson, R.M., Kamp, L., Matson, D.L., Irwin, P.G.J., Baines, K.H., Boryta, M.D., Leader, F.E., Jaumann, R., Smythe, W.D., Sotin, C., Clark, N., Cruikshank, D.P., Drossart, P., Pearl, J.C., Hapke, B.W., Lunine, J., Combes, M., Bellucci, G., Bibring, J.P., Capaccioni, F., Cerroni, P., Coradini, A., Formisano, V., Filacchione, G., Langevin, R.Y., McCord, T.B., Mennella, V., Nicholson, P.D. and Sicardy, B., 2007. Saturn's Titan: Searching for Surface Change. AGU Fall Meeting, \#P22B-03.

Porco, C.C., Baker, E., Barbara, J., Brahic, A., Burns, J.A., Charnoz, S., Cooper, N., Dawson, D.D., Del Genio, A.D., Denk, T., Dones, L., Dyudina, U., Evans, M.W., Giese, B., Grazier, K., Helfestein, P., Ingersoll, A.P., Jacobson, R.A., Johnson, T.V., McEwen, A., Murray, C.D., Neukum, G., Owen, W.M., Perry, J., Roatsch, t., Spitale, J., Sqyures, S., Thomas, P.C., Tiscareno, M., Turtle, E., Vasavada, A.R., Veverka, J., Wagner, R. and West, R., 2005. Cassini Imaging Science: Initial Results on Phoebe and Iapetus. Science, 307, 1237-1242.

Radebaugh, J., et al., 2008. Dunes on Titan observed by Cassini Radar. Icarus, 194, 690-703.

Radebaugh, J., 2009 Linear dunes on Titan and earth: Initial remote sensing comparisons. GEOMOR02903(IN PRESS).

Roe, H.G., Pater, I., Gibbard, S.G., Macintosh, B.A., Max, C.E., Young, E.F., Brown, M.E and Bouchez, A.H., 2004. A new 1.6-micron map of Titan's surface. Geophysical research letters, 31, L17S03.

Rosi, M., Lupi, L., Papale, P., Stoppato, M., 2003. Volcanoes. Firefly Books.

Sotin, C., buratti, B.J., Brown, R.H., Clark, R.N., Soderblom, L.A., Baines, K.H., Bellucci, G., Bibring, J.P., Capacciono, F., Cerroni, P., Combes, M., Coradini, A., Cruikshank, D.P., Drossart, P., Formisano, V., Langevin, Y., Matson, D.L., McCord, T.B., Nelson, R.M., Nicholson, P.D., Sicardy, B., Lemouelic, S., Rodriguez, S., Stephan, K and Scholz, C.K., 2005. Release of volatiles from a possible cryovolcano from near-infrared imaging of Titan. Nature, 435, 786-789.

Stofan, E.R., Lunine, J.I., Lopes, R., Paganelli, F., Lorenz, R.D., Wood, C.A., Kork, R., Wall, S., Elachi, C., Soderblom, L.A., Istro, S., Janseen, M., Radebaugh, J., Wye, L., Zebker, H., Anderson, Y., Allison, M., Boehmer, R., Callahan, P., Encrenaz, P., Flamini, E., Francescetti, G., Gim, Y., Hamilton, G., Hensley, S., Jonson, W.T.K., Kelleher, K., Muhleman, D., Picardi, G., Posa, F., Roth, L., Seu, R., Shaffer, S and Stiles, B., 2006. Mapping of Titan: Results from the first Titan radar passes. Icarus, 185, 443-456.

Stofan, E.R., Elachi, C., Lunine, J.I., Lorenz, R.D., Stiles, B., Mitchell, K.L., Ostro, S., Soderblom, L., Wood, C., Zebker, H., Wall, S., Janssen, M., Kirk, R., Lopes, R., Paganelli, F., Radebaugh, J., Wye, L., Anderson, Y., Allison, M., Boehmer, R., Callahan, P., Encrenaz, P., Flamini, R., Francescetti, G., Gim, Y., Hamilton, G., Hensley, S., Johnson, W.K.T., Kelleher, K., Muhleman, D., Paillou, P., Picardi, G., Posa, F., Roth, L., Seu, R., Shaffer, S., Vetrella, S., West, E., 2007. The lakes of Titan. Nature, 445, 61-64.

Wagner, R. J., Neukum, G., Giese, B., Roatsch, T. and Denk, T., 2007. Geology and Geomorphology of Rhea: a First Look at the High-Resolution Cassini ISS Images from the Targeted Flyby on Aug. 30, 2007. AGU Meeting abstract \#P12B-06. 
APPENDIX

Table A. Horizontal distances of ejecta for angles $0-80^{\circ}$ and several values of velocity range.

\begin{tabular}{|c|c|c|c|}
\hline Eruption velocity $(\mathrm{m} / \mathrm{s})$ & Angle of ejecta trajectory & Distance $(\mathrm{m})$ & Total distance $(\mathrm{m})$ \\
\hline \multirow[t]{8}{*}{35,2} & 0 & 0 & 0 \\
\hline & 10 & 835,43 & 835,43 \\
\hline & 20 & 681,85 & 1517,28 \\
\hline & 35 & 708,18 & 2225,47 \\
\hline & 45 & 818,09 & 3043,56 \\
\hline & 60 & 531,31 & 3574,87 \\
\hline & 70 & 897,01 & 4471,89 \\
\hline & 80 & 200,80 & 4672,68 \\
\hline \multirow[t]{8}{*}{39,3} & 0 & 0,00 & 0,00 \\
\hline & 10 & 1041,38 & 1041,38 \\
\hline & 20 & 849,94 & 1891,33 \\
\hline & 35 & 882,77 & 2774,09 \\
\hline & 45 & 1019,77 & 3793,86 \\
\hline & 60 & 662,30 & 4456,16 \\
\hline & 70 & 1118,15 & 5574,30 \\
\hline & 80 & 250,30 & 5824,60 \\
\hline \multirow[t]{8}{*}{48,3} & 0 & 0,00 & 0,00 \\
\hline & 10 & 1572,97 & 1572,97 \\
\hline & 20 & 1283,80 & 2856,77 \\
\hline & 35 & 1333,38 & 4190,15 \\
\hline & 45 & 1540,32 & 5730,48 \\
\hline & 60 & 1000,37 & 6730,85 \\
\hline & 70 & 1688,92 & 8419,76 \\
\hline & 80 & 378,06 & 8797,82 \\
\hline \multirow[t]{8}{*}{58,6} & 0 & 0,00 & 0,00 \\
\hline & 10 & 2315,37 & 2315,37 \\
\hline & 20 & 1889,73 & 4205,10 \\
\hline & 35 & 1962,71 & 6167,81 \\
\hline & 45 & 2267,32 & 8435,13 \\
\hline & 60 & 1472,52 & 9907,65 \\
\hline & 70 & 2486,04 & 12393,70 \\
\hline & 80 & 556,50 & 12950,19 \\
\hline \multirow[t]{8}{*}{66,3} & 0 & 0,00 & 0,00 \\
\hline & 10 & 2963,83 & 2963,83 \\
\hline & 20 & 2418,97 & 5382,80 \\
\hline & 35 & 2512,40 & 7895,20 \\
\hline & 45 & 2902,31 & 10797,51 \\
\hline & 60 & 1884,92 & 12682,43 \\
\hline & 70 & 3182,30 & 15864,73 \\
\hline & 80 & 712,35 & 16577,08 \\
\hline
\end{tabular}




\begin{tabular}{|c|c|c|c|}
\hline Eruption velocity $(\mathrm{m} / \mathrm{s})$ & Angle of ejecta trajectory & Distance $(\mathrm{m})$ & Total distance $(\mathrm{m})$ \\
\hline 70,8 & 0 & 0 & 0 \\
\hline & 10 & 3379,81 & 3379,81 \\
\hline 20 & 2758,48 & 6138,29 \\
\hline 35 & 2865,02 & 9003,31 \\
\hline & 45 & 3309,66 & 12312,98 \\
\hline 60 & 2149,48 & 14462,45 \\
\hline 70 & 3628,94 & 18091,40 \\
\hline & 80 & 812,33 & 18903,73 \\
\hline & & \\
\hline & 0 & 0,00 & 0,00 \\
\hline & 10 & 4272,21 & 4272,21 \\
\hline & 20 & 3486,82 & 7759,03 \\
\hline & 35 & 3621,49 & 11380,52 \\
\hline & 45 & 4183,53 & 15564,05 \\
\hline & 60 & 2717,02 & 18281,07 \\
\hline & 70 & 4587,12 & 22868,19 \\
\hline & 80 & 1026,82 & 23895,01 \\
\hline
\end{tabular}

